\title{
Bacteriological Profile (Aerobic) of Burn Wound Infection with Its Antibiotic Sensitivity Testing in Silchar Medical College and Hospital
}

\author{
Manashi Bora ${ }^{1^{*}}$ and Debadatta Dhar (Chanda) ${ }^{2}$ \\ ${ }^{1}$ Department of Microbiology, Jorhat Medical College \& Hospital, India \\ ${ }^{2}$ Department of Microbiology, Silchar Medical College \& Hospital, India \\ *Corresponding author
}

\begin{abstract}
A B S T R A C T
Burn wounds are highly susceptible to colonization and infection which creates obstacle in proper management of burn victims. Since burn wound infection shows changing trends in kathogenicity of microorganisms as well as their antibiotic sensitivity, hence, it is crucial to perform frequent evaluation of the burn wound to ensure early and appropriate therapy in burn patients. The study was conducted to find out the common organisms in infected burn wound samples and their antibiotic sensitivity pattern. The study was conducted in department of Microbiology and Surgery of Silchar Medical College and Hospital between July, 2015 and June, 2016. Pus samples and wound swabs collected from the hospitalized burn patients were processed according to standard microbiological techniques and Antibiotic sensitivity testing was done using Kirby Bauer's Disc diffusion technique according to C.L.S.I guideline. Out of 100 pus samples collected from patients admitted in burn unit, $79(79 \%)$ cases were culture positive, while $21(21 \%)$ were sterile. Out of 79 organisms isolated, $31(39.24 \%)$ were Pseudomonas aeruginosa, 21 (26.58\%) were Staphylococcus aureus, 14 (17.72\%) were Klebsiella pneumoniae, 8 (10.13\%) were Klebsiella oxytoca and $5(6.33 \%)$ were Proteus mirabilis. The Gram positive organism showed maximum sensitivity towards Vancomycin and Linezolid (100\%) and minimum towards Ampicillin (28.57\%) while gram negative isolates showed maximum sensitivity to Imipenem (100\%) and minimum towards Ampicillin(17.24\%). The high prevalence of antimicrobial resistance emphasizes the need to strengthen the infection control practices along with regular and periodical monitoring and surveillance activities to restrict emerging trend of antimicrobial resistance.
\end{abstract}

Burn wound infection,

Pseudomonas aeruginosa, Antibiotic sensitivity testing, Infection control practices.

Article Info

Accepted:

15 June 2018

Available Online:

10 July 2018

\section{Introduction}

Infected burn wounds are not only associated with a delay in epidermal maturation and deep scar formation but also prolongs the hospital stay of the patient and increases the chances of mortality due to sepsis, when compared to non-infected patients. ${ }^{1}$ Most of the burn victims, who survive including the initial 24 hours after burns, succumb to burn infection and its complications. Immediately following the thermal injury, the burn wounds are sterile; but eventually get Colonized with microorganisms. ${ }^{2}$ Various factors responsible 
are disruption of the skin barrier, a large cutaneous bacterial load, the possibility of the normal bacterial flora becoming opportunistic pathogens and severe depression of the immune system. All these factors contribute towards the sepsis in a burn victim. ${ }^{3}$ The pattern of infection differs from hospital to hospital; the bacterial flora of infected wound may change considerably during the healing period. $^{4,5}$

Microorganisms are transmitted to the burn wound surfaces by the hands of personnel, by fomites and possibly by hydrotherapy. ${ }^{6}$ The gastrointestinal tract is a potential reservoir for organisms that infect burn wounds, and it is likely that endogenous microbes are transmitted to burn wound surfaces by faecal contamination. 7 Earlier, Streptococcus pyogenes was the most frequent isolate from infected burn wounds. Currently, the common pathogens isolated from burn wounds are Staphylococcus aureus, Pseudomonas aeruginosa, Streptococcus pyogenes, coliforms, Acinetobacter spp., and others like anaerobic bacteria and fungi. ${ }^{8,9}$

Good infection control practices have a great impact on survival rate of burn patients. Emerging antimicrobial resistance in burn wound bacterial pathogens represent a serious therapeutic challenge for clinicians treating these patients. In order to overcome this problem continuous microbiological surveillance is needed. ${ }^{10}$

So this study is conducted to isolate and identify the common organisms causing burn wound infection and to determine their antibiotic sensitivity pattern to provide empirical treatment for favourable outcome.

\section{Materials and Methods}

Study design: Observational study (Crosssectional study).
Study area: Silchar Medical College \& Hospital (Microbiology \& Surgery Department)

Study Period: One year from July 2015 to June2016.

Inclusion criteria: All pus samples/ wound swabs collected from the hospitalized burn patients.

Exclusion criteria:1) Patients on antibiotic therapy.

2) Patient with wounds caused by other than burns

Study population: Pus samples in the form of wound swabs were collected from patients admitted in burn unit of Department of Surgery, Silchar Medical College \&Hospital. Patients of any age and both the sexes were included in this study.

Number of specimen: A total of 100 pus samples were collected.

A detailed history was taken with reference to name, age, sex, religion, hospital number, chief complaints, past history, underlying disease, antibiotic history etc. and all these informations were recorded in a pre-designed proforma.

The collected samples were processed for identification of organisms using standard microbiological techniques and biochemical test. All strains were tested for antimicrobial susceptibility testing using C.L.S.I guidelines. Under strict aseptic condition pus samples from burn wounds were collected in the form of swabs in sterile test tubes. The collected samples were immediately transferred to Bacteriology section of Department of Microbiology, Silchar Medical College \& Hospital for processing. The samples were at 
first inoculated into culture media and then direct smears were prepared. The direct smears were then subjected to Gram staining.

Smear were prepared from the specimen in clean grease free glass slides, dried and then heat fixed. Gram staining of the smear was done according to the methods described by Duguid JP(2006). ${ }^{11}$ It was examined for the presence of any bacteria and pus cells.

For primary isolation of bacteria the specimens were inoculated into the following media:

1)5\% sheep blood agar media

2)MacConkey agar media

The media were prepared as per methods described by Collee et al., (2006). ${ }^{12}$

The inoculated blood agar and MacConkey agar media were incubated aerobically at $37^{\circ} \mathrm{C}$ for 24 hours. If no growth was observed after 24 hours incubation then it was reincubated for another 24 hours after which if there was no growth it was considered sterile.

After incubation, identification of bacterium from positive cultures was done with a standard microbiological technique which includes motility testing by hanging drop preparation, gram staining and biochemical reactions such as catalase, coagulase, indole, methylred, Voges-Proskauer, citrate, urease, Phenyl pyruvic acid test and oxidase test. Further biochemical tests done were carbohydrate fermentation test using Lactose, sucrose, mannitol and Maltose, Triple sugar Iron test, Nitrate reduction test, Arginine dihydrolase production, lysine and ornithine decarboxylase test, Hugh and leifson test.

The antimicrobial susceptibility testing were done by Kirby Bauer's Disk Diffusion method and interpreted as per Clinical Laboratory
Standard Institution (CLSI) guidelines. Mueller Hinton agar (MHA) was used as media, it was inoculated with a suspension of organisms equivalent to 0.5 McFarland turbidity standard and discs were applied. Maximum six (6) antimicrobial discs were put in the $100 \mathrm{~mm}$ diameter MHA plate and plates were incubated at $37^{0} \mathrm{C}$ overnight ${ }^{13}$.

The antibiotic discs used were purchased from HiMedia Lab Pvt. Ltd. Inhibition zones were measured and reported as sensitive or resistant according to manufacturer's literature.

Klebsiella pneumoniae ATCC 700603, Pseudomonas aeruginosa ATCC 27853, Staphylococcus aureus ATCC 25923 were used as quality control strain. Antibiotic discs were used for determination of sensitivity by Kirby- Bauer disc diffusion test.

For gram positive organisms Vancomycin, Linezolid, Cefoxitin, Cefotaxime and Penicillin and for gram negative organisms Imipenem, Piperacillin/Tazobactum, Aztreonam, Ceftazidime and Cefuroxime were exclusively used in this study.

\begin{tabular}{|l|l|}
\hline Antibiotic- concentration/disc & $\begin{array}{l}\text { Antibiotic- concentration/ } \\
\text { disc }\end{array}$ \\
\hline IMIPENEM(IPM)-10mcg & $\begin{array}{l}\text { CEFTRIAXONE(CTR)- } \\
30 \mathrm{mcg}\end{array}$ \\
\hline AMPICILLIN(AMP)-10mcg & AMIKACIN(AK)-30mcg \\
\hline LINEZOLID(LZ)-30mcg & AZTREONAM(AT)- 30mcg \\
\hline VANCOMYCIN(VA)-30 mcg & GENTAMICIN(GEN)- \\
& 10mcg \\
\hline AMOXYCLAV(AMC)-30mcg & LEVOFLOXACIN(LE)- \\
& 5mcg \\
\hline PIPERACILLIN/TAZOBACTAM & CIPROFLOXACIN(CIP)- \\
(PIT)100/10 mcg & 5mcg \\
\hline CEFOTAXIME(CTX)-30mcg & CEFUROXIME(CXM)- \\
& $30 \mathrm{mcg}$ \\
\hline CEFOXITIN(CX)-30mcg & PENICILLIN(PE)-10 units \\
\hline CEFTAZIDIME (CAZ)-30mcg & \\
\hline
\end{tabular}

\section{Results and Discussion}

Out of 100 samples collected, 79(79\%) cases were culture positive, while $21(21 \%)$ were sterile. Out of 100 patients 30 burn patients 
(30\%) are in the age group of 20-29 years which is the most common age group found in this study followed by 22 patients between 3039 years, 19 patients between 0-9 years, 13 patients between 40-49 years, 10 patients between 10-19 years, 4 patients above 59 years and 2 patients between 50-59 years respectively. Out of 79 culture positive cases, $21(26.58 \%)$ cases were caused by gram positive organisms, while $58(73.42 \%)$ cases were caused by gram negative organisms. Out of 79 culture positive cases, Pseudomonas aeruginosa 31(39.24\%), Staphylococcus aureus 21(26.58\%), Klebsiella pneumoniae 14 (17.72\%), Klebsiella oxytoca $8(10.13 \%)$ and Proteus mirabilis 5(6.33\%). Gram positive isolate showed maximum sensitivity towards Vancomycin and Linezolid (100\%) followed by Ciprofloxacin (85.71\%), Cefoxitin (80.95\%), Gentamicin (76.19\%), Levofloxacin (71.43\%), Amikacin (71.43\%), AmoxicillinClavulanic acid (66.67\%), Ceftriaxone (61.9\%), Penicillin (42.85\%), Cefotaxime (38.09\%) and Ampicillin (28.57\%). MRSA detected was $19.05 \%$. The gram negative isolates showed maximum sensitivity to Imipenem (100\%) followed by Ciprofloxacin (84.48\%), Levofloxacin (81.03\%), Ceftriaxone (67.24\%), Aztreonam (67.24\%), Piperacillin/Tazobactum (65.52\%), Amikacin
(62.06\%), Ceftazidime (58.62\%), Cefuroxime (56.89\%), Gentamicin (53.45\%), Amoxycillin-Clavulanic acid (41.38\%) and Ampicillin (17.24\%).

Infection is the most important problem in the treatment of burns. Burns become infected because the environment at the site of the wound is ideal for the multiplication of infecting organisms. The immune-suppressive status of the patient, immediate lack of antibodies, plentiful supply of moisture and nutrients in the physical environment; the temperature and gaseous requirements etc. are ideal for the growth of microorganisms. ${ }^{6,7}$

Burn wound infections are showing changing trends in the relative importance and cyclic Pathogenicity of microorganisms as well as their antimicrobial sensitivities. To ensure early and appropriate therapy in burn patients, a frequent evaluation of the wound is necessary. Thus, a continuous surveillance of microorganisms and their antibiotic susceptibility patterns is essential to maintain good infection control programmes in the burn unit, thus improving the overall infection related morbidity and mortality. ${ }^{14}$

Table.1 Age wise distribution of burn patients

\begin{tabular}{|l|l|l|}
\hline AGE GROUP & NO. OF CASES & CULTURE POSITIVE \\
\hline 0-9 YEARS & 19 & 12 \\
\hline 10-19 YEARS & 10 & 9 \\
\hline 20-29 YEARS & 30 & 21 \\
\hline 30-39 YEARS & 22 & 20 \\
\hline 40-49 YEARS & 13 & 11 \\
\hline 50-59 YEARS & 2 & 2 \\
\hline >59 YEARS & 4 & 4 \\
\hline
\end{tabular}


Table.2 Distribution of isolates based on gram staining

\begin{tabular}{|l|l|l|}
\hline Isolates & Number & Percentage \\
\hline Gram positive & 21 & $26.58 \%$ \\
\hline Gram negative & 58 & $73.42 \%$ \\
\hline Total & 79 & $100 \%$ \\
\hline
\end{tabular}

Table.3 Different organisms isolated

\begin{tabular}{|l|l|l|}
\hline ORGANISM & NUMBER & PERCENTAGE \\
\hline Pseudomonas aeruginosa & 31 & $39.24 \%$ \\
\hline Staphylococcus aureus & 21 & $26.58 \%$ \\
\hline Klebsiella pneumoniae & 14 & $17.72 \%$ \\
\hline Klebsiella oxytoca & 8 & $10.13 \%$ \\
\hline Proteus mirabilis & 5 & $6.33 \%$ \\
\hline TOTAL & 79 & $100 \%$ \\
\hline
\end{tabular}

Table.4 Distribution of patients based on total burn surface area

\begin{tabular}{|l|l|l|}
\hline Total Burn SurfaceArea(TBSA) & NO. OF CASES & PERCENTAGE \\
\hline$<\mathbf{2 5 \%}$ & 44 & $44 \%$ \\
\hline $\mathbf{2 5 - 5 0} \%$ & 38 & $38 \%$ \\
\hline $\mathbf{5 1 - 7 5 \%}$ & 11 & $11 \%$ \\
\hline$>\mathbf{7 5 \%}$ & 7 & $7 \%$ \\
\hline TOTAL & 100 & $100 \%$ \\
\hline
\end{tabular}

Table.5- Distribution of patients based on type of burn

\begin{tabular}{|l|l|l|}
\hline TYPE OF BURN & NO. OF PATIENTS & PERCENTAGE \\
\hline FLAME BURN & 71 & $71 \%$ \\
\hline SCALD BURN & 14 & $14 \%$ \\
\hline ELECTRIC BURN & 15 & $15 \%$ \\
\hline TOTAL & 100 & $100 \%$ \\
\hline
\end{tabular}

Table.6 Sensitivity pattern of Gram positive isolate (Staphylococcus aureus)

\begin{tabular}{|c|c|c|c|c|c|c|c|c|c|c|c|c|c|}
\hline ORGANISM & $\begin{array}{c}\text { TOTAL } \\
\text { NO }\end{array}$ & CIP & LE & GEN & AMP & CTR & CTX & CX & AMC & $\mathbf{P E}$ & AK & $\mathbf{L Z}$ & VA \\
\hline S.aureus & 21 & 18 & 15 & 16 & 6 & 13 & 8 & 17 & 14 & 9 & 15 & 21 & 21 \\
\hline PERCENTAGE & & $\begin{array}{c}85.71 \\
\%\end{array}$ & $\begin{array}{c}71.43 \\
\%\end{array}$ & $\begin{array}{c}76.19 \\
\%\end{array}$ & $\begin{array}{c}28.57 \\
\%\end{array}$ & $61.9 \%$ & $\begin{array}{c}38.09 \\
\%\end{array}$ & $\begin{array}{c}80.95 \\
\%\end{array}$ & $\begin{array}{c}66.67 \\
\%\end{array}$ & $\begin{array}{c}42.85 \\
\%\end{array}$ & $\begin{array}{c}71.43 \\
\%\end{array}$ & $\begin{array}{c}100 \\
\%\end{array}$ & $\begin{array}{c}100 \\
\%\end{array}$ \\
\hline
\end{tabular}


Table.7 Sensitivity pattern of Gram negative isolates

\begin{tabular}{|l|l|l|l|l|l|l|l|l|l|l|l|l|l|}
\hline Organism & $\begin{array}{l}\text { Total } \\
\text { No }\end{array}$ & CIP & LE & GEN & AMP & AK & CTR & PIT & CAZ & CXM & AMC & AT & IMP \\
\hline P.aeruginosa & 31 & 27 & 25 & 15 & 5 & 16 & 22 & 19 & 18 & 17 & 10 & 20 & 31 \\
\hline K.pneumoniae & 14 & 11 & 12 & 9 & 2 & 11 & 9 & 10 & 8 & 8 & 8 & 10 & 14 \\
\hline K.oxytoca & 8 & 7 & 6 & 5 & 2 & 6 & 5 & 6 & 5 & 5 & 4 & 6 & 8 \\
\hline P.mirabilis & 5 & 4 & 4 & 2 & 1 & 3 & 3 & 3 & 3 & 3 & 2 & 3 & 5 \\
\hline Total no & 58 & 49 & 47 & 31 & 10 & 36 & 39 & 38 & 34 & 33 & 24 & 39 & 58 \\
\hline Percentage & & $84.48 \%$ & $81.03 \%$ & $53.45 \%$ & $17.24 \%$ & $62.06 \%$ & $67.24 \%$ & $65.52 \%$ & $58.62 \%$ & $56.89 \%$ & $41.38 \%$ & $67.24 \%$ & $100 \%$ \\
\hline
\end{tabular}

Fig.1 Pie diagram showing culture results

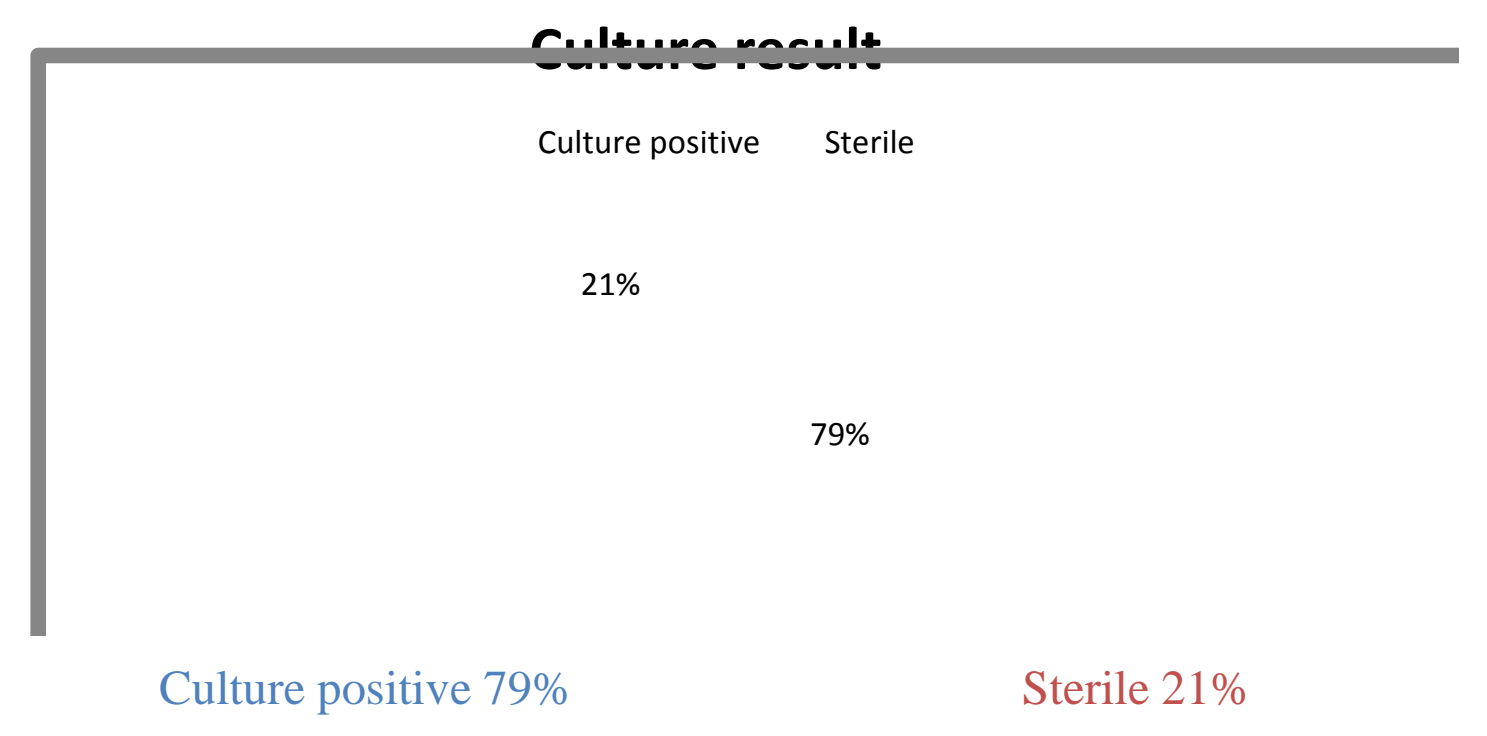


In this study out of 100 samples from burn patients $79(79 \%)$ samples were culture positive. This finding is comparable to findings of Kaushik et al., ${ }^{15}$, AL -Bdour et al., ${ }^{16}$, Idomir et al., ${ }^{17}$, Dash et al., ${ }^{18}$, Saxena et al., 5, Modi et al., ${ }^{14}$, Magnet et al., ${ }^{19}$ and Sharma et al., ${ }^{20}$. In Kaushik et al., ${ }^{15}$ culture positivity was 293 out of 336 samples i.e. $(87.2 \%)$. Culture positivity of AL-B dour MN et al., ${ }^{16}$ was $84.6 \%$, Idomir et al., ${ }^{17}$ was $86.2 \%$, Dash et al., ${ }^{18}$ was $88.6 \%$, Saxena et al., ${ }^{5}$ was $70.33 \%$ i.e. 147 out of 209 samples showed culture positivity, Modi et al., ${ }^{14}$ was $85.7 \%$, Magnet et al., ${ }^{19}$ showed $66.66 \%$ i.e. 100 out of 150 samples showed positive growth and Sharma et al., ${ }^{20}$ showed $87.96 \%$ positive culture.

In other studies, conducted by Agnihotri et al., ${ }^{21}$, Begum et al., ${ }^{22}$, Mamani et al., ${ }^{23}$, Kulkarni et al., ${ }^{24}$, Shrivastava et al., ${ }^{25}$, rate of culture positivity were high compared to present study. Culture positivity showed by Agnihotri et al., ${ }^{21}$ was $96 \%$, Begum et al., ${ }^{22}$ was $92.85 \%$, Mamani et al., ${ }^{23}$ was $93.3 \%$. In Kulkarni et al., ${ }^{24} 83$ out of 91 samples i.e. $91.2 \%$ showed positive growth and in Shrivastava et al., ${ }^{25} 109$ out of 118 samples i.e. $92.37 \%$ showed positive culture.

While studies conducted by Vaez et al., ${ }^{26}$ and Mohamed et al., ${ }^{27}$ found comparatively low rate of culture positivity of $31 \%$ and 60 \%respectively.

In the present study, gram negative organisms were the predominant pathogens constituting $73.42 \%$ case.

This finding is in concordance with Kulkarni et al., ${ }^{24}$, Vaez et al., ${ }^{26}$ and Sharma et al., ${ }^{20}$. However studies conducted by Komolafe et al., ${ }^{28}$ and Idomir et al., ${ }^{17}$ found higher percentage of gram positive organisms compared to gram negative organisms.
In the present study the most common organism isolated was Pseudomonas aeruginosa which constituted $39.24 \%$ of total organisms followed by Staphylococcus aureus $(26.58 \%)$. This finding correlates with studies conducted by Kaushik et al., ${ }^{15}$, Agnihotri et al., ${ }^{21}$, Rajput et al., ${ }^{4}$, Dash M et al., ${ }^{18}$,Saxena et al., ${ }^{5}$ and Magnet et al., ${ }^{19}$.

However in study conducted by Srinivasan et al., ${ }^{29}$ the most common organism was Klebsiella $(33.91 \%)$, in Vindenes et al., ${ }^{30}$ the most common organism was Coagulase negative Staphylococcus (21.5\%) and in study conducted by Bayram Y et al., ${ }^{31}$ the most common organism was Acinetobacter baumannii (23.6\%) which is dissimilar to present study.

Among the gram positive isolates, Linezolid and Vancomycin are found to be most effective drugs showing $100 \%$ sensitivity to all isolates. Similar observation was made by Sharma et al., ${ }^{20}$ where gram positive isolates were $100 \%$ sensitive to Vancomycin and Linezolid.

In studies conducted by Ahsan et al., ${ }^{32}$ and Bhama et al., ${ }^{33}$ Pseudomonas aeruginosa was $100 \%$ sensitive to Imipenem which is similar to present study. However studies like Dash et al., ${ }^{18}$, Saxena et al., ${ }^{5}$ and Behesti et al., ${ }^{34}$ low rate of sensitivity was found which were $90.8 \%, 95.77 \%$ and $38.9 \%$ respectively. Since burn wound infection shows changing trends in pathogenecity of microorganisms as well as their antibiotic sensitivity, hence, it is crucial to perform frequent evaluation of the burn wound to ensure early and appropriate therapy in burn patients. Also, the high prevalence of antimicrobial resistance emphasizes the need to strengthen the infection control practices along with regular and periodical monitoring and surveillance activities to restrict emerging trend of antimicrobial resistance. 
This study concludes that in vitro testing of antibiotics prior to its use may help to prevent multidrug resistant organisms in burn infection which will help in reducing morbidity and mortality of burn patients.

\section{References}

1. Singer AJ, McClain SA. Persistent wound infection delays epidermal maturation and increases scarring in thermal burns. Wound Repair and Regeneration. Blackwell Science Inc; 2002 Nov 1;10(6):372-7.

2. Church D, Elsayed S, Reid O, Winston B, Lindsay R. Burn wound infections. Clin Microbiol Rev. 2006;19:403-34.

3. Jones WG, Minei JP, Barber a E, Rayburn JL, Fahey TJ, Shires GT. Bacterial translocation and intestinal atrophy after thermal injury and burn wound sepsis. Annals of surgery [Internet]. 1990 Apr;211(4):399-405

4.Rajput A, Singh KP, Kumar V, Sexena R, Singh RK. Antibacterial resistance pattern of aerobic bacteria isolates from burn patients in tertiary care hospital. Biomedical research. 2008 Jan 1;19(1):1-4.

5. Saxena N, Dadhich D, Maheshwari D, Saxena N. Aerobic Bacterial isolates from burn wound infection patients and their antimicrobial susceptibility pattern in Kota, Rajasthan. J Evol Med Dent Sci. 2013 Jun 10;2(23):4156-60.

6. Bagdonas R, Tamelis A, Rimdeika R, Kiudelis M. Analysis of burn patients and the isolated pathogens. Lithuanian Surgery 2004; 2(3): 190-193.

7. Mayhall CG. The Epidemiology of Burn Wound Infections: Then and Now. Clinical Infectious Diseases 2003; 37: 543-550.

8. Chaudhary U, Goel N, Sharma M, Griwan MS, Kumar V. Methicillin-resistant
Staphylococcus aureus Infection/Colonization at the Burn Care Unit of a Medical School in India. J Infect Dis Antimicrob Agents 2007; 24(1): 29-32.

9. Lawrence JC. Burn bacteriology during the last 50 years. Burns 1994; 18: 23-29.

10. Patil P, Joshi S, Bharadwaj R. Aerobic bacterial infections in a burns unit of Sassoon General Hospital, Pune. International $\mathrm{J}$. of Healthcare and Biomedical Research. 2015 Apr;3(03):106-12.

11. Duguid JP. Staining methods. Mackie \& McCartney Practical Medical Microbiology. $14^{\text {th }}$ edition. Churchill Livingstone;2006:793-811.

12. Collee JG, Marr W. Specimen collection, culture container and media. Mackie \& McCartney Practical Medical Microbiology.14 ${ }^{\text {th }}$ edition. Churchill Livingstone;2006:95-111.

13. CLSI. Performance Standards for Antimicrobial Susceptibility Testing; Twenty-Fourth Informational Supplement. CLSI document M100S24. Vol.34. Wayne, PA: Clinical and Laboratory Standards Institute; 2014.

14. Modi S, Anand AK, Chachan S, Prakash

S. Bacteriological profile and antimicrobial susceptibility patterns of isolates from burn wounds at a tertiary care hospital in Patna. Journal of Evolution of Medical and Dental Sciences. 2013 Aug 26;1(2):6533-41.

15. Kaushik R, Kumar S, Sharma R, Lal P. Bacteriology of burn wounds - the first three years in a new burn unit at the Medical College Chandigarh. Burns. 2001 Sep 30;27(6):595-7.

16. AL-Bdour MN, Arabiyat L, Alkatib M, Almaytah K, Haddadin W. Microorganisms in Burn Wounds. Infectious Disease Journal of Pakistan. 2011 Apr 1;20(2).

17. Idomir M, PIRĂU R, Nemet C, Badea M. 
Evaluation of microbiological spectrum of burn wound infections. Med. Sci. 2012 Jan 1;5(1):7-12.

18. Dash M, Misra P, Routaray S. Bacteriological profile and antibiogram of aerobic burn wound isolates in a tertiary care hospital, Odisha, India. Int. J. Med. Med Sci. 2013;3(5):460-3.

19. Magnet MD, Khan A, Arongozeb M, Ahmed Z. Isolation and identification of different bacteria from different types of burn wound infections and study their antimicrobial sensitivity pattern. IJRANSS. 2013 Aug;1(3):125-32.

20.Sharma S, Kumar M, Parihar G. A Study of Bacterial Profile and Antibiotics Resistance Pattern of Various Clinical Isolates in Wound Swabs of Hospitalised Burn Patients at Tertiary Care Hospital. International Journal of Scientific Research. 2016 Mar 19;5(3).

21. Agnihorti N, Gupta V, Joshi RM. Aerobic bacterial isolates from burn wound infections and their antibiograms. Burns. 2004;30:241-243.

22. Begum H, Quamruzzaman M, Talukdar M. Microbial Isolates from Patients and their Antibiogram at the Tertiary care Burn Unit in Bangladesh. Journal of Bangladesh College of Physicians \& Surgeons. 2011 Apr 1;29(2):62.

23.Mamani M, Derakhshanfar A, Niayesh A, Hashemi SH, Yousefi MR, Zavar S. Frequency of bacterial burn wounds infection and antimicrobial resistance in burn center of Bessat hospital of Hamedan.Iranian Journal of Surgery,Spring 2009,Vol. 17.

24.Kulkarni V, Arali SM, Jayaraj YM, Shivannavar CT, Joshi MR. Bacterial etiology and their antibiogram in burn wound infections at Kalaburgi region (India). Indian Journal of Burns. 2015
Jan 1;23(1):65.

25.Shrivastava G, Bhatambare GS, Lunawat A, Patel KB, Maheshwari T. Pattern of microorganism from burn wounds and their trends of susceptibility to antibiotics in tertiary care center. International Journal of Health System and Disaster Management. 2016 Apr .;4(2):53.

26. Vaez H, Beigi F. Antibiotic susceptibility patterns of aerobic bacterial strains isolated from patients with burn wound infections. Germs. 2016 Mar;6(1):34.

27. Mohamed H. One year prevalence of critically ill burn wound bacterial infections in surgical ICU in Egypt: Retrospective study. Egyptian Journal of Anaesthesia. 2016 Apr 25.

28. Komolafe OO, James J, Kalongolera L, Makoka M (2003) Bacteriology of burns at the Queen Elizabeth Central Hospital, Blantyre, Malawi. Burns 29: 235-238

29.Srinivasan, S., Vartak, A. M., Patil, A., \& Saldanha, J. Bacteriology of the burn wound at the Bai Jerbai Wadia Hospital for children, Mumbai, India-A 13-year study, Part IBacteriological profile. Indian Journal of Plastic Surgery: Official Publication of the Association of Plastic Surgeons of India, 42(2), 213218. http://doi.org/10.4103/09700358.59284

30.Vindenes H,Bjerknes R.Microbial colonization of large wounds.Burns.1995;21(8): 575-9.

31.Bayram Y, Parlak M, Aypak C, Bayram I. Three-year review of bacteriological profile and antibiogram of burn wound isolates in Van, Turkey. Int J Med Sci. 2013 Jan 1;10(1):19-23.

32.Ahsan MM, Gupta AK, Zea MI, Yaseen M. A Study of Changing Pattern of Bacterial Flora and Antimicrobial 
Resistance in Patients with Major Burns. International Journal of Contemporary 2016;4(1):172-7.

33.Bhama S, Rajan R, Theodore RB. A study on bacterial profile of burn wound infections. Journal of The Academy of
Clinical Microbiologists. 2013 Jul 1;15(2):54.

34.Beheshti S, Zia M. Bacteriology of burns and antibiogram in an Iranian burn care center. African Journal of Pharmacy and Pharmacology. 2011 Apr 30;5(4):538-41.

\section{How to cite this article:}

Manashi Bora and Debadatta Dhar (Chanda). 2018. Bacteriological Profile (Aerobic) of Burn Wound Infection with Its Antibiotic Sensitivity Testing in Silchar Medical College and Hospital. Int.J.Curr.Microbiol.App.Sci. 7(07): 2130-2139. doi: https://doi.org/10.20546/ijcmas.2018.707.250 